\title{
Folate and Vitamin B-12 status of anemic pregnant women and association to hemoglobin during antenatal care, 17-37 weeks in Ambo Hospital, Oromia, Ethiopia, a multi regression analysis of socio-economic and serum folate and Vitamin B-12.
}

\author{
Teshome Bekele Elema ${ }^{1,2^{*}}$, Kaleab Baye Yimam ${ }^{1}$, Feyyisa Chala Waka $^{3}$, Bikila Nagasa Olana ${ }^{3}$ \\ ${ }^{1}$ Center for Food Science and Nutrition, Addis Ababa University, Oromia, Ethiopia \\ ${ }^{2}$ Food Science and postharvest Technology, Arsi University, Ethiopia \\ ${ }^{3}$ Ethiopian Public Health Institute, Addis Ababa, Ethiopia
}

\begin{abstract}
Maternal health during pregnancy has been very critical and important for intergenerational health. According to WHO about half of anemia is believed to be due to iron deficiency anemia. In Ethiopia, the anemia prevalence was reported $22 \%$ in pregnant and believed due to IDA. Despite recommendation of iron-folic acid supplementation adherence is still low. The objective of the research was to determine the prevalence of folate and vitamin B-12 deficiency among pregnant and association to anemia during second and third trimester. A cross-sectional hospital-based design was conducted to complete this research. 104 pregnant women were selected based on the current altitude adjusted hemoglobin status after informed consent form is signed from each participant. Serum folates, vitamin B-12 were determined using ECLIA and C-reactive protein by Cobas Integra e411. Serum folate, vitamin B-12 and CRP were defined as deficient below 3 $\mathrm{ng} / \mathrm{mL}, 150 \mathrm{pg} / \mathrm{mL}$ and greater than $5 \mathrm{mg} / \mathrm{L}$ respectively. Data were coded and analyzed using SPSS 22 version. About half of pregnant women were with formal education. $68.1 \%$ of pregnant women were anemic based on cutoff point $(\mathrm{Hgb}<10.9 \mathrm{~g} / \mathrm{dL})$. Study participants deficiencies were observed in $\mathbf{2 7 . 9 \%}$ for folate, $26.9 \%$ for vitamin B-12 and $23.1 \%$ for CRP based on WHO cut-off point. There is a positive association between folate and hemoglobin, low awareness among elder pregnant but, no association between age and hemoglobin value. There is high prevalence of CRP in comparison to previous studies. Supplementation of vitamin B-12 will be recommended including further research on risk factors including rural residents to strength the finding.
\end{abstract}

Keywords: Anemia; Folate; Vitamin B-12; CRP; Pregnancy; Micronutrients

Accepted on February $16^{\text {th }}, 2018$

\section{Introduction}

Maternal health during gestation has been very serious and imperative for intergenerational health. Anemia is a public and community health concerns that touching 2 billion society's worldwide [1]. Anemia affects suspiciously women in developing countries, and is self-determining factor for diminished quality of life, rise morbidity and mortality, particularly in the third trimester. According to WHO, about half of the anemia is supposed to be due to iron deficiency anemia (IDA). However, besides iron deficiency, defects in numerous other micronutrients including vitamin $\mathrm{A}$, folate, Vitamin B-12 and possibly zinc also cause anemia [2,3]. In Ethiopia, the incidence of anemia amongst pregnant women was again reported to be $22 \%$ [4], which suggests that anemia is a moderate public health concern [5].

Nutrition in most developing countries is principally plant based with little consumption of animal source foods. This leads to an increased risk of multiple micronutrients deficiencies, especially at life style like pregnant when physiological demands are substantially increased [6,7]. Moreover, such plant-based diets contain significant amount of mineral absorption inhibitors like phytate and polyphenols that impair the bioavailability of micronutrients. Despite all this and WHO's recommendation that pregnant women take a prophylactic dose of $30-60 \mathrm{mg}$ of Iron/Iron-folic acid supplementation, adherence to these recommendation, particularly in developing countries like Ethiopia have been very low [8]. Although anemia could also be due to other micronutrient deficiencies, multiple micronutrients supplementations are not yet proposed and not available for pregnant women.

The first thousand days, starting from conception to the child's second birthday, is a critical window of opportunity for nutritional interventions that aim to improve pregnancy, birth and developmental consequences. This is a period when a child's brain, organs and body is rapidly developing [9]. Anemia during pregnancy has been associated with complication in pregnancy outcomes and countless risk of low birth weight, which itself has been linked to adverse physical and cognitive growth. In Ethiopia, the leading cause for the poor adherence to iron supplementations was reported to beside effects $[10,11]$. Therefore, it is crucial to correct anemia during pregnancy. More importantly little is known about the etiology of anemia in most developing countries including Ethiopia. The 
Citation: Elema TB, Yimam KB, Waka FC, et al. Folate and Vitamin B-12 status of anemic pregnant women and association to hemoglobin during antenatal care, 17-37 weeks in Ambo Hospital, Oromia, Ethiopia, a multi regression analysis of socio-economic and serum folate and Vitamin B-12. J Nutr Hum Health. 2018;2(1):28-34

investigation of the etiology of anemia during third trimester pregnant women by quantifying serum folate and vitamin B-12 in addition to dietary intake is necessary to recognize nutritional deficiencies with inevitability $[12,13]$. The purpose of this study was to investigate the prevalence of folate and vitamin B-12 deficiency and dietary intake of anemic pregnant women attending antenatal care during second and third trimester in the Ambo Hospital of the west shows zone, Ethiopia.

\section{Subject and Methods}

The cross sectional Institutional based design was carried out between December 2014 and June 2015 in Ambo, a west Showa zone of Oromiyaa region, located at $115 \mathrm{~km}$ from Addis Ababa to determine the prevalence of anemia, serum folate and vitamin B-12 status of pregnant woman attending ANC during the second and third trimester. The study population was composed of pregnant women attending the regular pregnancy ANC during the second and third trimester. The study area is found at a longitude of $37^{\circ} 32^{\prime}$ to $38^{\circ} 3^{\prime} \mathrm{E}$, and latitude of $8^{\circ}$ $47^{\prime}$ to $9^{\circ} 20^{\prime} \mathrm{N}$ and the altitude range is from 1900 to 2275 meters above sea level. The climatic condition of the area is $23 \%$ highland, $60 \%$ midland, and $17 \%$ lowland. It has an annual rainfall ranging from $800-1000 \mathrm{~mm}$ and temperature ranging from $20^{\circ} \mathrm{C}$ to $29^{\circ} \mathrm{C}$.

Agriculture is the main occupation of the population of the area. The study population consisted of a sample of all second and third trimester pregnant women attending ANC at Ambo hospital. But, any women with pregnancy related complications such as history of diabetes mellitus, hypertension, those on iron supplements, history of blood transfusion within the last 3 months were excluded. The dependent variable is Hemoglobin level and Ecological, physiological and biochemical indices are considered as independent factors.

\section{Sample size and sampling technique}

Among 206 pregnant women screened for analysis during ANC service, 104 anemic pregnant women were selected for further biochemical analysis based on hemoglobin value in considering Hemo-dilution. Sample size was determined based on the EDHS 2011 [14] the prevalence of anemia among the women aged 1549 in Oromiyaa region is $19.3 \%$. The maximum permissible limit is $19.2 \%$ of " $p$ " and standard normal value $(z=1.96)$. Using the single population proportion formula with a $95 \% \mathrm{CI}$ $(d=0.95)$ and $5 \%$ margin of error sample size was calculated and obtained 238. But, the researcher has planned to collect sample from 250 pregnant women to increase accuracy of data. Within the specified period only 206 of pregnant women were registered with hemoglobin result of below $11.5 \mathrm{~g} / \mathrm{dl}$. Due to resource limitation (financial and time constraint) the principal investigator was forced to consider homo-dilution and accepted the anemic pregnant women hemoglobin value below $10.5 \mathrm{~g} /$ $\mathrm{dl}$ [15]. Based on the above consideration 104 pregnant women sample were selected for further investigation of micronutrient analysis.

\section{Ethical considerations}

The research was ethically cleared from Addis Ababa University Institutional Health and Research Ethical Review
Board committee in College of Natural Science and further the research ethically approved regional Health Research Ethical Review Committee.

\section{Sample collection}

Socio-demographic characteristics: Verbal informed consent was obtained from all the participants and a semi-structured questionnaire was given in Afan Oromo language to gather information including age, time of previous gestation, and maternally related characteristic, present and past history in nutritional assessment of anemic pregnant women and dietary habit.

Management/handling of the experimental unit and sample collection process: Blood sample (ca. $4 \mathrm{~mL}$ ) was drawn into vacutainer tubes without anticoagulants by medical laboratory technicians from the antecubital vein. Gestational ages were considered by the reported last menstrual period and examining of fundal height by experienced midwives at maternal and child health, MCH of Hospital [16,17].

Hemoglobin test and altitude adjustment: Hemoglobin tests were performed from the fresh blood sample before centrifugation. Separate vacutainer tube without EDTA was used for whole blood sample collection for the analysis of complete blood count (CBC) by ADVIA 2120i 5 Part Cell Counter (Siemens). A hemoglobin level was used to define anemia by adjusting for altitude according WHO $\mathrm{Hb}$ adjustment formula [18]. $\mathrm{Hb}$ adjustment $=-0.032 \times($ Altitude $\times 0.0032808)$ $+0.022 \times(\text { Altitude } \times 0.0032808)^{2}$. Considering hemo -dilution of pregnancy based on WHO and international guidelines, anemia was then defined as $\mathrm{Hgb}<10.9 \mathrm{~g} / \mathrm{dl}$ in pregnant women $[19,20]$. After correction, severe, moderate and mild anemia was defined as $\mathrm{Hgb}$ below 7gm/dL, 7-9.9 gm/dl and 9.9-10.9 $\mathrm{gm} / \mathrm{dl}$ respectively [21]. The sample collected into the tube was allowed to clot and centrifuged at $3000 \times \mathrm{g}$, for $15 \mathrm{~min}$ to extract serum for biochemical analysis and stored at $-20^{\circ} \mathrm{C}$ until analyzed [22]. A sample collected into a tube was allowed to store and transported within a maximum of 3 days for biochemical analysis of serum folate and B-12.

\section{Laboratory analysis}

Determination of iron biomarkers: Serum vitamin B-12 and folate concentrations were measured using ECLIA [22]. Serum CRP was determined using the Nephelometry Assay method by Cobas Integrate 411 by using Liquid, ready-to-use reagents [23]. Based on the WHO cut-off point folate and B-12 were deficient considering Serum folate and B-12 deficiencies were defined as levels below $3 \mathrm{ng} / \mathrm{mL}$ and $150 \mathrm{pg} / \mathrm{mL}$ respectively. Inflammation in pregnant women was determined assuming serum CRP greater than $5 \mathrm{mg} / \mathrm{L}$ [24].

\section{Statistical analysis}

The data were coded and analyzed with the Statistical analyses using SPSS (version 22; SPSS Inc., Chicago, IL) software [22]. The Pearson correlation coefficient was used to measure the strength of the linear relationship between normally distributed variables. Descriptive analyses of categorical variables were reported and $\mathrm{p}<0.05$ at $\alpha=0.05$ denoted a statistically significant difference in all statistical comparisons. To analyze 
the differences between groups, the independent student $t$ test was used for continuous variables, among mild and moderate anemic participant and between second and third trimester anemic pregnant women. Pearson's correlation was used to examine correlation between hemoglobin and serum folate and B-12 [21].

\section{Results}

\section{Socio-demographic characteristics, correlation and regression analysis}

Socio-demographic characteristics: Socio-demographic of all mothers $(n=206)$ attended ANC during the study period is presented Table 1 . The mean \pm SD of gestational age was $23.3 \pm$ 5.6 weeks, mean age of the pregnant women was $24.6 \pm 5.03$. All the study participants were Christians and $95.6 \%$ were married. Only $57.8 \%$ had had their own latrine and 50\% had formal education. Based on the socio-demographic data collected, 35 $(17 \%)$ of pregnant women were infected with malaria at least once in the past two years.

Pregnancy history and complications in the current pregnancy: Based on the Table $2 \dagger^{*}$ report, previous pregnancy history only $1.9 \%$ were delivered into their babies within the interval of less than 2 years and $91(44.2 \%)$ was pregnant for the first time. More than one-third of the study participants $(34.5 \%)$ were received information about nutrition and about $12.6 \%$ of participants had faced blood loss during previous pregnancy. Based on the Table $3 \dagger^{*}$ report, $36.5 \%$ of study participants were not taking any iron or IFA supplementation at all. Hence, $63.5 \%$ of the participants were taken either iron or iron-folic acid supplementation but not more than one month. Increased breathing, especially on routine activity 71 (34.5\%) and headaches $57(27.7 \%)$ were the two leading signs of symptoms

Table 1. Selected ecological indicator characteristics of the pregnant woman attending ANC.

\begin{tabular}{|c|c|c|c|}
\hline Characteristics* & Mean \pm SD & $(\mathrm{N}=\mathbf{2 0 6})$ & $(\%)$ \\
\hline \multicolumn{4}{|c|}{ Age of Participant } \\
\hline $15-19$ & \multirow{4}{*}{$24.6 \pm 5.03$} & 82 & 39.8 \\
\hline $20-25$ & & 50 & 24.3 \\
\hline $26-30$ & & 52 & 25.2 \\
\hline $31+$ & & 22 & 10.7 \\
\hline \multicolumn{4}{|c|}{ Marital Status } \\
\hline Married & & 197 & 95.6 \\
\hline Not Married & & 9 & 4.4 \\
\hline \multicolumn{4}{|c|}{ Gestational Age } \\
\hline 14-26wks (2) & \multirow{2}{*}{$23.3 \pm 5.6$} & 137 & 66.5 \\
\hline $27-37$ wks (3) & & 69 & 33.5 \\
\hline \multicolumn{4}{|c|}{ Occupation } \\
\hline Farmer & & 62 & 30.1 \\
\hline House wife & & 113 & 54.9 \\
\hline Merchant & & 31 & 15 \\
\hline \multicolumn{4}{|c|}{ Educational Status } \\
\hline Illiterate & & 75 & 36.4 \\
\hline Read and Write & & 28 & 13.6 \\
\hline With formal education & & 103 & 50 \\
\hline \multicolumn{4}{|c|}{ Owns Latrine } \\
\hline Yes & & 119 & 57.8 \\
\hline No & & 86 & 42.2 \\
\hline
\end{tabular}

* The socio-demographic characteristic includes all pregnant women attended ANC during 2nd and 3rd trimester $(\mathrm{N}=206)$
Table 2. Maternal pregnancy history $(n=206)$

\begin{tabular}{|c|c|c|}
\hline Characteristics* & Frequency & $\%$ \\
\hline \multicolumn{3}{|c|}{ Previous deliveries History } \\
\hline First pregnancy & 91 & 44.2 \\
\hline Health Institution & 50 & 24.3 \\
\hline Home & 65 & 31.6 \\
\hline \multicolumn{3}{|c|}{ Information about Nutrition } \\
\hline Yes & 71 & 34.5 \\
\hline No & 135 & 65.5 \\
\hline \multicolumn{3}{|c|}{ Blood Loss } \\
\hline Yes & 26 & 12.6 \\
\hline No & 180 & 87.38 \\
\hline \multicolumn{3}{|c|}{ Interval between babies } \\
\hline$<2$ year & 2 & 1.9 \\
\hline$>2$ year & 113 & 54.85 \\
\hline
\end{tabular}

* The maternal pregnancy history includes all pregnant women attended ANC during 2 nd and $3^{\text {rd }}$ trimester $(\mathrm{N}=206)$

Table 3. Complications related to the current pregnancy $(n=206)$

\begin{tabular}{|c|c|c|}
\hline Characteristics $^{*}$ & Frequency & $\%$ \\
\hline \multicolumn{3}{|l|}{ Use of Contraceptive* } \\
\hline Yes & 126 & 61.2 \\
\hline \multicolumn{3}{|l|}{ No } \\
\hline \multicolumn{3}{|l|}{ Iron or Folate Supplementation } \\
\hline Iron Supplementation & $25 \dagger$ & 23.6 \\
\hline Iron-folic acid (IFA) supplementation & $41 \dagger$ & 39.4 \\
\hline No Supplementation & 38 & 36.5 \\
\hline \multicolumn{3}{|l|}{ Sign of Symptoms } \\
\hline Persistent swelling of feet, hands or face & 24 & 11.7 \\
\hline Increasing breathing, especially on routine activity & 71 & 34.5 \\
\hline Headaches & 57 & 27.7 \\
\hline Blurring of Vision & 29 & 14.1 \\
\hline Fever temperature $>38 \mathrm{C}$ & 6 & 2.9 \\
\hline High Colored urine in the past two weeks & 10 & 4.9 \\
\hline No Symptoms & 9 & 4.4 \\
\hline \multicolumn{3}{|c|}{$\begin{array}{l}\text { * Only data in use of contraceptive include all the } 206 \text { pregnant women in } 2^{\text {nd }} \text { and } \\
3^{\text {rd }} \text { trimester } \\
\text { † Out of } 104 \text { anemic pregnant women none of them took IFA supplementation } \\
\text { more than one month }\end{array}$} \\
\hline
\end{tabular}

and $14.1 \%$ had blurred vision during the current pregnancy. This finding has also supported the statement of anemia during pregnancy has been attributed not only due to increased iron requirements during the second and third trimester of gestation, but also due to effects of physiological state as well as also described in a study of pregnant women in Ugandan [25].

Dietary assessment and nutritional status of respondents: Regarding food consumption and dietary pattern, $87.9 \%$ $(\mathrm{n}=181)$ of the participants was received at least three meals a day. Few (5.3\%) of mothers were missing their breakfast during the fasting period. Animal source foods were consumed by less than half of the respondents (Table 4).

\section{Prevalence of micronutrient deficiency (folate and vitamin $B-12)$ deficiencies among pregnant women attending ANC}

The prevalence of selected micronutrients was presented in Table 5 and the mean hemoglobin values of anemic pregnant women were $10.5 \pm 1.2 \mathrm{~g} / \mathrm{dL}$. Mean $\pm \mathrm{SD}$ of serum folate, serum vitamin B-12 and serum CRP were noted as $7.6 \pm 3.5$ (ng/ $\mathrm{mL}), 187.4 \pm 53.7(\mathrm{pg} / \mathrm{mL})$ and $4.5 \pm 1.6(\mathrm{mg} / \mathrm{L})$, respectively. Vitamin B-12 is prevalent in $26.9 \%$ (B-12 deficiency $<150 \mathrm{pg} /$ 
Citation: Elema TB, Yimam KB, Waka FC, et al. Folate and Vitamin B-12 status of anemic pregnant women and association to hemoglobin during antenatal care, 17-37 weeks in Ambo Hospital, Oromia, Ethiopia, a multi regression analysis of socio-economic and serum folate and Vitamin B-12. J Nutr Hum Health. 2018;2(1):28-34

$\mathrm{mL}$ ), Folate is deficient in $27.9 \%$ (serum folate $<6.8 \mathrm{ng} / \mathrm{mL}$ ) and $23.08 \%$ had acute inflammation based on the serum CRP $>5 \mathrm{mg} / \mathrm{L}$.

\section{Prevalence of micronutrient deficiency and CRP infection anemic pregnant women}

The mean and prevalence of micronutrient status of pregnant women categorized by the severity of anemia (mild or moderate) is presented in Table 6. From the data below, no statistically significant difference was observed between mild and moderate anemic pregnant women. Based on the category of GA as presented in Table 7. Except for CRP values, no significant difference was detected in serum folate and B-12 composition between the second and the third trimester.

\section{Prevalence of anemia based on folate, vitamin B-12 and $C$-reactive protein of pregnant women attending $A N C$}

Among the anemic pregnant women $(n=104), ~ 71 \%$ were in the $2^{\text {nd }}$ trimester, whereas $29 \%$ in the $3^{\text {rd }}$ trimester of pregnancy.

Table 4. Reported food groups consumed during the period of current pregnancy $(n=206)^{*}$

\begin{tabular}{|c|c|c|}
\hline \multicolumn{2}{|c|}{ Characteristics* $^{*}$ Frequency } & $\%$ \\
\hline Frequency of meals per day \\
\hline 2 per day & 25 & 12.1 \\
\hline 3 per day & 181 & 87.9 \\
\hline \multicolumn{2}{|c|}{ Level of Fasting } \\
\hline Deprivation of animal source foods except fish & 30 & 14.6 \\
\hline Deprivation of all animal source foods & 32 & 15.5 \\
\hline Deprivation of animal Source foods and no breakfast & 11 & 5.3 \\
\hline No fasting & 62 & 59.6 \\
\hline Drink alcohol during pregnancy & \\
\hline Yes & 51 & 24.8 \\
\hline No & 155 & 75.24 \\
\hline
\end{tabular}

* Data of food group includes all pregnant women attended ANC during 2nd and 3rd trimester

Table 5. Prevalence of micronutrient deficiencies among anemic pregnant women attending $(n=104)$

\begin{tabular}{|c|c|c|c|}
\hline Characteristics* & Frequency & $\%$ & Mean + SD \\
\hline Altitude adjusted $\mathrm{Hb}$ & 206 & & $10.5 \pm 1.2^{*}$ \\
\hline $\mathrm{Hb}(<10.9 \mathrm{~g} / \mathrm{dL})$ & 104 & 50.48 & $9.7 \pm 0.66$ \\
\hline Serum Folic acid & 104 & & $7.6 \pm 3.5$ \\
\hline $\mathrm{FAD}(<6.8 \mathrm{ng} / \mathrm{ml})$ & 29 & 27.9 & \\
\hline Serum Vitamin B12 & & & $187.4 \pm 53.7$ \\
\hline Vit B12 deficiency (<150 pg/mL) & 28 & 26.9 & \\
\hline Serum CRP & & & $4.5 \pm 1.6$ \\
\hline Presence of inflammation CRP $(>5.0 \mathrm{mg} / \mathrm{L})$ & 24 & 23.1 & \\
\hline Presence of inflammation CRP (<5.0 mg/L) & 82 & 78.85 & \\
\hline
\end{tabular}

Table 6. Micronutrient status of pregnant women with mild and moderate anemia $(n=104)$

\begin{tabular}{|c|c|c|c|c|c|c|c|}
\hline \multirow{3}{*}{ Characteristics* } & \multicolumn{5}{|c|}{ Types of anemia } & \multicolumn{2}{|c|}{$\begin{array}{l}95 \% \mathrm{Cl} \text { of the } \\
\text { difference }\end{array}$} \\
\hline & \multicolumn{2}{|c|}{ Moderate } & \multicolumn{2}{|r|}{ Mild } & \multirow{2}{*}{$p$-value } & \multirow{2}{*}{ lower } & \multirow{2}{*}{ upper } \\
\hline & $\mathbf{N}$ & Mean +SD & $\mathbf{N}$ & Mean + SD & & & \\
\hline Serum FA & 59 & $7.9 \pm 3.7$ & 45 & $7.2 \pm 3.4$ & 0.296 & -0.653 & 2.122 \\
\hline Serum B12 & 59 & $178.8 \pm 46.5$ & 45 & $198.6 \pm 60.5$ & 0.072 & -41.41 & 1.838 \\
\hline Serum CRP & 59 & $4.5 \pm 1.7$ & 45 & $4.4 \pm 1.5$ & 0.642 & -0.487 & 0.786 \\
\hline
\end{tabular}

Folate and B-12 was severe in $17.31 \%$ and $26.92 \%$ respectively. The remaining $82.69 \%$ and $73.08 \%$ were under a risk of deficiency. But 24 (34\%) had high inflammation based on serum CRP (Table 8).

\section{Discussion}

\section{Socio-demographic characteristics}

Maternal under-nutrition diminishes a woman's productivity, causing repercussions for this woman, her family, her community, and the broader society. Daba et al., [26] reported that educational level, monthly income and nutrition information during pregnancy were identified as important predictors of knowledge of women on nutrition during pregnancy among the study participants. Due to the third trimester covers the $28^{\text {th }}$ week onwards till delivery the severity of anemia is directly proportional to the occurrence of complications in pregnancy. Etiologic pattern is often complex in second and third trimester $[16,17]$. Based on the previous pregnancy history delivery recorded there is no significant association due to the interval between babies, to use of contraceptive and history of blood loss to hemoglobin value. According to the study of Obse et al., [27] decreasing gap between previous birth, had caused an increase in the magnitude of anemia. Opposite to the Obse finding there was no association between previous birth and hemoglobin status in the current finding. This might be due to all the participant's history of birth interval was greater than two years and the study respondents are from the similar status (all are anemic).

\section{Anemia and micronutrient status of pregnant women}

For comparison of each micronutrient status categorized by age according to the present finding, severity of anemia has almost increased as the age of the respondent's increases; this finding also supported by Obse et al., [27]. Serum folate was significantly associated with serum $\mathrm{B}-12(\mathrm{r}=0.27 ; \mathrm{P}=0.02)$, No significant relation was observed between moderately and mildly anemic mothers considering both folate and B-12 concentration. This indicated that folic acid deficiency and vitamin B-12 deficiency is not the only cause of anemia during pregnancy $[16,17]$.

But, serum folic acid and CRP status were recorded lower in the older pregnant women. The study conducted by Kefiyalw et al., [28] stated that the prevalence of anemia was higher in pregnant women in the age group of 18-26. This might be due to Kefyalew's study included all status of pregnant women (anemia and non-anemic). According to Gibson et al., [24] the study conducted in Southern Ethiopia a high prevalence of protein and zinc deficiency was observed and two-third of pregnant women were anemic in the area were no cellular animal products consumed. This study might have an advantage over the previous study, but, due to all participants are from the same group (anemic) still no correlation and any prediction was obtained from the current data. Deficiency of vitamin B-12 in the current study also agreed with the deficiency that conducted in southern Ethiopia and in Nepal [2,27].

\section{C-reactive protein inflammatory status and anemia}

Regarding the infection of pregnant women based on serum CRP the prevalence of inflammation was very high in comparison to 
Table 7. Micronutrient status of pregnant women between second and third trimester anemic women ( $n=104)$

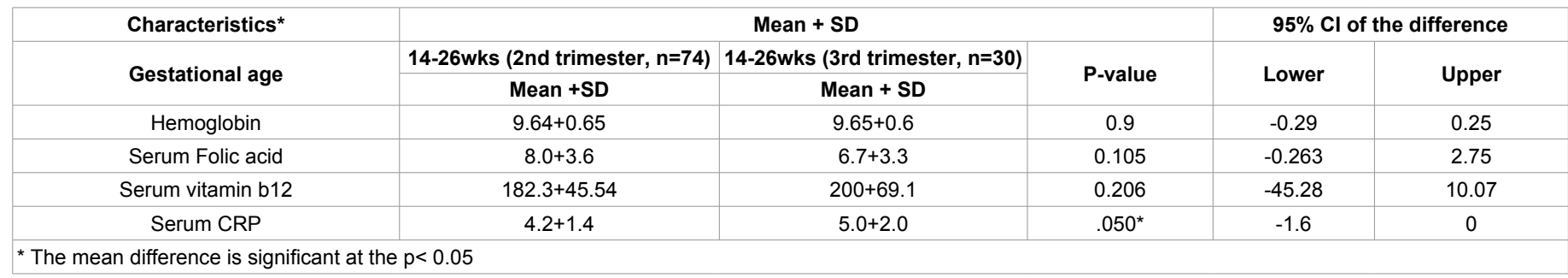

Table 8. Prevalence description of folate, vitamin B12 and C-reactive protein of pregnant women attending ANC.

\begin{tabular}{|c|c|c|c|c|c|c|}
\hline & \multirow{2}{*}{ Total } & \multirow{2}{*}{ Sub Total } & & & Moderate anemia, $\mathrm{Hb}<9.9$ & Mild anemia $\mathrm{Hb}<10.9$ \\
\hline & & & & Sum \% & N (\%) & $N(\%)$ \\
\hline \multirow{2}{*}{ Gestational Age * } & \multirow{2}{*}{206} & 74 & $14-26 w k s$ & 71.15 & $41(69.5)$ & $33(73.3)$ \\
\hline & & 30 & $27-37 w k s$ & 28.85 & $16(15.4)$ & $4(3.8)$ \\
\hline \multirow{3}{*}{ Serum Folic acid } & \multirow{3}{*}{104} & 18 & Severe & 17.31 & $8(7.7)$ & $10(9.6)$ \\
\hline & & 11 & Possible & 10.58 & $5(4.8)$ & $6(5.8)$ \\
\hline & & 74 & Normal & 71.15 & $45(43.3)$ & $29(27.9)$ \\
\hline \multirow{3}{*}{ Serum Vitamin B12 } & \multirow{3}{*}{104} & 28 & Severe & 26.92 & $18(30.5)$ & $10(9.6)$ \\
\hline & & 46 & Moderate & 44.23 & $29(27.9)$ & $17(16.4)$ \\
\hline & & 30 & Normal & 28.85 & $12(11.5)$ & $18(17.3)$ \\
\hline \multirow{2}{*}{ Serum CRP } & \multirow{2}{*}{104} & 80 & $\mathrm{sCRP}<5$ & 76.92 & $47(45.2)$ & $33(31.7)$ \\
\hline & & 24 & $\mathrm{sCRP}>5$ & 23.08 & $12(11.5)$ & $12(11.5)$ \\
\hline
\end{tabular}

study conducted in southern Ethiopia. In a study conducted by in Uganda similar result was reported. According to the CRP concentration was markedly raised and nearly the two-third of the women had elevated CRP [26,27]. In the current finding based on the CRP values Infection/inflammation was higher in the third trimester [29]. In Malawi also, the same result was recorded which agreed with the finding of the present study [30]. The contradiction of findings with might be due differences in study participants (only anemic pregnant included in this study). Iron deficiency and malaria are significantly interrelated and affecting developing world especially in pregnancy was explained in another finding and supported by this finding. Whereas anemia was associated with markers of infections in another research finding from Tanzania also and in another finding, anemia was significantly associated with elevated CRP, with an odds ratio of 2.74 [31].

\section{Micronutrient interrelations}

The Pearson correlation showed a significant negative association between the age of a woman and IFA supplementation $(\mathrm{r}=-0.20$; $\mathrm{p}=0.04$ ). The negative association of age of women and ironfolic acid supplementation indicated that the older women's awareness of IFA supplementation was low compared with the younger women. On the other hand, serum CRP was positively correlated with vitamin $\mathrm{B}-12(\mathrm{r}=0.26 ; \mathrm{p}=0.01)$. In the correlation analysis of selected socio-demographic with prevalence of anemia with adequate iron store (anemic only based on $\mathrm{Hb}$ value) as a dependent variable there are not a significant correlation between selected socio-demographic data and biochemical analysis.

\section{Correlation and regression analysis of $\mathrm{Hb}$ and $\mathrm{B}-12$}

Logistic regression analysis was used to assess the association between hemoglobin and folate. There was also a negative correlation between age of women and hemoglobin value $(\mathrm{r}=$ $0.26 ; \mathrm{p}=0.04)$; whereas there was a positive correlation between IFA supplementation and $\mathrm{Hb}$. This show that iron and FAD might be the causes for depletion of $\mathrm{Hb}$. Surprised that there was a positive correlation between IFA supplementation and serum folic acid.

\section{Factors affecting and predictors in severity of anemia}

Positive correlation was found between serum CRP and serum B-12 $(\mathrm{r}=0.32 ; \mathrm{p}=0.02)$ in moderately anemic pregnant women. According to Gebremedhin et al., [8] in level indicates infection/inflammation only $8.4 \%$ of the pregnant women had elevated serum CRP (CRP $\geq 6 \mathrm{mg} / \mathrm{L}$ ). Among up to date finding conducted in the southern Ethiopia by Gibson et al., [24] showed that none of the biochemical indices of folate or vitamin B-12 status, were significant predictors of hemoglobin concentrations. This finding was not supported by this study. This might be due to the frequent consumption of folate rich fermented enset in southern Ethiopia. Because in Sidama Zone of Southern Ethiopia, maize (Zea mays L.) and fermented enset (Enset ventricosum) products are the major staple foods, contributing up to $90 \%$ of energy. In the current study the older the woman had the least hemoglobin $(9.40 \pm 0.94)$, serum folate $(6.09 \pm 2.97)$ and CRP $(3.8 \pm 0.8)[16,17,32]$.

\section{Conclusion}

The prevalence of anemia among third trimester anemic pregnant women in this study compared with second trimester anemic pregnant women was high. Study participants had high inflammation/infection based on serum CRP $>5 \mathrm{mg} / \mathrm{L}$. The older pregnant women were observed more deficient almost in all micronutrients than younger women. The high prevalence of vitamin B-12 deficiency more than expected might be due to less amount of B-12 required and the supplementation of folic 
Citation: Elema TB, Yimam KB, Waka FC, et al. Folate and Vitamin B-12 status of anemic pregnant women and association to hemoglobin during antenatal care, 17-37 weeks in Ambo Hospital, Oromia, Ethiopia, a multi regression analysis of socio-economic and serum folate and Vitamin B-12. J Nutr Hum Health. 2018;2(1):28-34

acid, which causes to increase in B-12 because they have the interrelation between them. The present study has shown that a clinical study of micronutrients iron biomarkers and vitamin deficiency is a hidden risk for pregnant women especially in second and third trimester.

In conclusion, this study helped us to understand the association between the level of anemia and the biosocial factors. Women in developing countries have a high prevalence of ID but also tend to be deficient in other micronutrients including vitamin B-12, folate and infection/inflammatory predictors. The current study has several advantages over previous Ethiopian studies that examined micronutrient status during pregnancy including study area.

\section{Recommendations}

The necessity for vitamin B-12 supplementation needs to be confirmed with prospective randomized trials from different regions of our country before the introduction of a fortification program for prevention of neural tube defect. The topical development of analytical means for examination of hepcidin in biological samples is providing an opportunity to include hepcidin as an innovative biomarker reflecting iron status and to that hepcidin concentration was positively correlated with ferritin and this test was recommended to be included in the future research. Further research on risk factors of anemia, which include rural residents, should be conducted to strengthen and broaden these findings.

\section{Limitation of the study}

This study has a few limitations, first, the nature of the study being a cross-sectional study design; it does not show risk factors in detail. Second, it is a hospital-based study with a relatively small sample size. Lack of comparison group (anemic with nonanemic). The pregnancy complications such as hypertension, blood sugar level and urinary albumin was not determined; even that study participants were not recalled their complications such as hypertension, blood sugar level and urinary albumin and no further interpretation of analysis was done in such complication factors. The current status of the mother somewhere else than Ambo health centers and Ambo hospital was not included. And lack of anthropometric measurement of participants and their infants are also other limitation.

\section{References}

1. Zimmermann MB, Chaouki N, Hurrell RF. Iron deficiency due to consumption of a habitual diet low in bioavailable iron: a longitudinal cohort study in Moroccan children. Am J Clin Nutr. 2005; 81(1): 115-21.

2. Bhandari S, Banjara MR. Micronutrients deficiency, a hidden hunger in Nepal: Prevalence, causes, consequences and solutions. Int Scholarly Research Notices. 2015: 9

3. WHO/UNICEF. Towards an integrated approach for effective anaemia control Joint statement by the World Health Organization and the United Nations Children's Fund, USA.

4. EDHS. Trends in maternal health in Ethiopia challenges in achieving the MDG for maternal mortality In-depth Analysis of the EDHS 2012; Addis Ababa, USA.

5. WHO/UNICEF/UNU. Iron deficiency anemia: Assessment, prevention, and control. Geneva, World Health Organization, 2001; USA.

6. WHO/FAO Report of a joint WHO/FAO expert consultation on diet, nutrition and the prevention of chronic diseases, WHO Library Cataloguing-in-Publication Data Geneva, Switzerland. 2003: 87-130.

7. FAO. Globalization of food systems in developing countries: Impact on food security and nutrition and a synthesis of country case studies. Development Policy Review. 2004; 2195-60: 21-56.

8. Gebremedhin S, Enquselassie F, Umeta M. Maternal anemia in Southern Ethiopia. Afr J Rep Heal. 2014; 18(1):47.

9. Samuel TM. Maternal Micro Nutrient deficiencies in early pregnancy and infant nutritional status in Urban South India. 2013, India.

10. Pavord S, Myers B, Robinson B, Allard S, Strong J, Oppenheimer C. UK guidelines on the management of iron deficiency in pregnancy. Br J Haematol. 2012; 156(5):588-600.

11. South Australian Perinatal Practice Guidelines, Chapter 60 Anemia in pregnancy, Australia.

12. Johnson TA. Luesley DM, Baker PN. Obstetrics and gynaecology: An evidence-based text for MRCOG. (2ndedn). Hodder Arnold, London. 2010; 139-43.

13. Pasricha SRS, Flecknoe BSC, Allen KJ. Diagnosis and management of iron deficiency anemia: A clinical update. Medi Jour of Australia. 2010; 193(9): 525-32.

14. Ethiopian Demographic and Health Survey Central Statistical Agency in Addis Ababa, Ethiopia ICF International Calverton, Maryland, USA. 2011: 180-6.

15. Naing L, Winn T, Rusli BN. Practical issues in calculating the sample size for prevalence studies. Arch Orofac Sci. 2006; 1: 9-14.

16. Gibson RS Principles of Nutritional Assessment, 2nd ed., Oxford University Press, New York, USA, Chapter 18, 22. 2005.

17. Food and Nutrition Board, Institute of Medicine. Dietary reference intakes for Vitamin A, Vitamin K, Arsenic, Boron, Chromium, Copper, Iodine, Iron, Manganese, Molybdenum, Nickel, Silicon, Vanadium and Zinc. National Academy of Sciences Press, Washington, DC, USA.

18. Sullivan KM, Mei Z, Strawn GL, et al. Hemoglobin adjustments to define anemia. Trop Med Int Health. 2008; 13(10): 1267-71.

19. Melku M, Addis Z, Alem M, et al. Prevalence and predictors of maternal anemia during pregnancy in Gondar, Northwest Ethiopia, 2014.

20. International nutritional anemia consultative group. Measurements of iron status. Nutrition Foundation, New York, USA. 1985. 
21. WHO, Worldwide Prevalence of Anemia 1993-2005: WHO Global Database on Anemia, WHO, Geneva, Switzerland. 2008.

22. Dilshad AK, Samia F, Rabia I, et al. Iron, Folate, and Cobalamine deficiency in anaemic pregnant females in tertiary care center at Rawalpindi J. Ayub Med Coll Abbottabad. 2010; 22(1).

23. Kimberly MM, Vesper HW, Caudill SP, et al. Standardization of immunoassays for measurement of highsensitivity CRP. Phase I: Evaluation of secondary reference materials. Clinical Chemistry. 2003; 49(4): 611-16.

24. Gibson RS, Abebe Y, Stabler S, et al. Zinc, gravida, infection, and iron, but not vitamin B-12 or folate status, predict hemoglobin during pregnancy in Southern Ethiopia. J Nutrition. 2008; 138(3): 581-86.

25. Baingana RK, Enyaru JK, Tjalsma H, et al. The etiology of anemia during pregnancy: A study to evaluate the contribution of iron deficiency and common infections in pregnant Ugandan women. J Public health Nutrition. 2014; 1-13.

26. Daba G, Beyene F, Fekadu H, et al. Assessment of knowledge of pregnant mothers on maternal nutrition and associated factors in Guto Gida Woreda, East Wollega Zone, Ethiopia. J Nutr Food Sci. 2013; 3(6): 235-42.

27. Obse N, Mossie A, Gobena T. Magnitude of anemia and associated risk factors among pregnant women attending antenatal care in Shalla Woreda, West Arsi Zone, Oromia Region, Ethiopia. Eth J Health Sci. 2013; 23(2): 165-73.

28. Hinderaker SG, Olsen BE, Lie RT, et al. Anemia in pregnancy in rural Tanzania: Associations with micronutrients status and infections. Eur J Clin Nutr. 2002; 56(3):192-9.

29. Kanago, Laree M, Kevin M. The relationship between anemia and biomarkers of inflammation (CRP and AGP) in women of Papua New Guinea 2011.

30. Martha AC, Morgan MG, Carla C. Influence of host iron status on Plasmodium falciparum infection. Front Pharmacol. 2014; 5: 84 .

31. Mahmood L. The metabolic processes of folic acid and Vitamin B-12 deficiency. J HealthRes Rev.2014;1(1): 1-9.

32. Koury MJ, Ponka P. New insights into erythropoiesis: The role of folate, vitamin B-12, and Iron. Annu Rev Nutr. 2004; 24: 105-31.

\section{*Correspondence to:}

Teshome Bekele Elema, M.Sc

Center for Food Science and Nutrition,

Addis Ababa University,

Oromia,

Ethiopia

Tel: +251911543975

E-mail: elemabekele@gmail.com 